\title{
DATING MORTAR BY OPTICALLY STIMULATED LUMINESCENCE: A FEASIBILITY STUDY
}

\author{
CHRISTIAN GOEDICKE \\ Humboldt-Universität zu Berlin, Geographisches Institut, Abt. Geomorphologie, \\ Rudower Chaussee 16, D-12489 Berlin, Germany
}

Received 17 May 2010

Accepted 31 August 2010

\begin{abstract}
Quartz is the datable component in mortar. Although its luminescence properties are very well studied, the problem of mortar dating arises from a low level of optical bleaching. In order to reduce the time consuming efforts for dating lime mortar in monuments by optically stimulated luminescence, we investigated the most suitable methods of dose and dose rate determination, and we explored tests which are suitable to predict the datability of a given material. Reverting to the large number of publications on sedimentary partially bleached quartz we found linear modulation techniques especially useful, equally we also recommend the determination of the level of optical depletion before starting analyses. Single grain analysis is regarded as an ultimate but infallible tool to date very poorly bleached quartz from mortar. Dose rate measurements need to take into account the radioactive equilibrium of the uranium decay and the short range inhomogeneity of the environmental gamma radiation field: gamma spectrometry and on-site TLD measurements are best suited.
\end{abstract}

Keywords: optical dating, monuments preservation, mortar.

\section{INTRODUCTION}

Soon after thermoluminescence became a dating tool for archaeological ceramics, its potential for dating brickwork was discovered by Fleming (1979). Architectural historians very much welcomed the new absolute dating method, as conventional methods such as stylistic investigation, documentary research and dendrochronology have limitations, whereas the error of radiocarbon dating often exceeds the required precision of architectural research. As a major advantage, this new method also includes secular buildings, for which documentary evidence is usually lacking.

However, thermoluminescence could not resolve all the dating problems of architectural historians. Besides the problem of re-use of brick material, encountered

Corresponding author: C. Goedicke

e-mail: christian.goedicke@t-online.de frequently by the Milan group (Martini and Sibilia, 2006), a category of buildings not constructed by fired bricks but from unfired natural materials (mud bricks, stone) could still not be dated. It is this category that actually receives great attention in actual architectural research. Hence, a reliable way to obtain unambiguous results is by dating materials that can be used only once for construction, e.g. mortar and render.

Mortar was first recognized as a suitable dosimeter for the reconstruction of accident doses after incidents of nuclear power plants by Bøtter-Jensen et al. (2000a). As mortar is an unfired material, dating was accomplished by using optically stimulated luminescence.

Because of its high content of carbon, mortar would ideally be suited for radiocarbon dating. In fact, a large number of relevant experiments have been carried out by means of accelerator mass spectrometry (AMS) (Hale et al., 2003; Nawrocka et al., 2005; Lindroos et al., 2007; 
Scharf, 2007). But despite noteworthy efforts, mortar dating by AMS has not become a routine method, as the chemical separation of calcite, formed during solidification of lime in historic periods, from geological calcite remains a problem. The use of wood, plant remains or charcoal particles, unintentionally mixed into the lime during manufacture, for AMS dating is successful if the contaminant material is contemporary, but fails when e.g. much older wood was used (Grootes, personal communication). Luminescence dating of mortar remains, therefore, a promising method.

In addition to the exhaustive presentation on brick dating by Bailiff (2007) the present paper describes the experiences gained during experiments to date mortar by optically stimulated luminescence (OSL). In view of the necessary experimental efforts, we investigated whether the success of mortar dating is predictable or whether the dating experiments can be stopped at an early stage.

\section{INSTRUMENTATION AND SAMPLES}

The roman city Mogontiacum, modern Mainz on the Rhine river, offers a large variety of architectural remains from which mortar samples can be removed in considerable size. Some of these are dated by historical records or archaeological evidence, such as brick stamps or coins, others still present open questions. Samples from Mogontiacum are, therefore, ideally suited for methodological studies. Well and not well behaving samples were encountered, i.e. samples yielding ages either in concordance with historical records or Holocene ages, indicating different sources of the raw material.

A first set of samples was collected from the Roman Theatre. Only lately this theatre was attributed to late antiquity on the basis of brick stamps, coins and an associated lime oven (Goedicke and Dolata, 2007). The ruins seem to present the last major monument built under Roman rule. Samples were taken from internal subconstruction pillars in form of large chunks $(>500 \mathrm{~g})$, denoted by MM1 to MM8.

From a Roman Bath, excavated at Triton Platz/Mainz in the sixties and now covered again by modern buildings, three samples, numbered TRI3, TRI4 and TRI6, were taken, two of which belonging to the well behaved category. Documentary evidence points to $33 \mathrm{AD}$ as the year of the erection of the building.

A controversy still exists as to the attribution of the Drusus Monument. The military commander died in $9 \mathrm{BC}$ during a campaign in Germania, but the date of the erection of the monument is unclear, mainly because no unambiguous junction could be established between written records and the monument as it is seen today. All the samples collected from the site (DRS1 to DRS4) proved not datable and could not resolve the controversy.

Conversely, the remains of the Roman Aqueduct are well dated, contemporary authors report that the Aqueduct was erected 70-80 AD to provide the Roman Bath with freshwater from a nearby village. Three samples (AQP1 and AQP3) were chosen mainly as reference material.

List of samples:

- Roman Theatre - MM1, MM2...(5)...MM8

- Drusus Monument - DRS1, DRS2, DRS3, DRS4

- Triton Platz-TRI3, TRI4, TRI6

- Aqueduct-AQP1, AQP3

Quartz fractions were extracted from the mortar samples by standard laboratory routines, i.e. etching by hydrofluoric $(38 \%)$ acid for $40 \mathrm{~min}$. To avoid vigorous reactions of the acid with calcite, it is recommended to destroy the calcite with hydrochloric acid before starting the etching process. An additional drying is necessary between the two steps. All the samples collected did not represent pure lime mortar, but opus caementicium, the roman form of concrete. In Mogontiacum this consists of lime mortar mixed with lime stones, bricks and coarse gravel. In this study no samples were used containing finely crushed brick material, as this may be of different age than the mortar.

Luminescence light was recorded by Risø readers, either DA-12 or DA-15. The readers were equipped with blue light emitting diodes ( $470 \mathrm{~nm}, \Delta 20 \mathrm{~nm}$ ) as stimulation devices, the emitted light was detected by an EMI 9635QA photomultiplier through a $7.5 \mathrm{~mm}$ Hoya U-340 glass filter.

\section{METHODS}

\section{Evaluation of the archaeological dose}

Dating mortar follows the same procedures which are also used for dating sediments. The special feature of mortar is, however, that it shows all the adversary properties known from sediments almost regularly, for instance partial bleaching, low signal and slow decay. Quartz is used as the dosimetric mineral which is present in mortar to more than $50 \%$. In contrast to the application of OSL dating in geology the zero-setting event, i.e. the event to be dated, is not bleaching on deposition or during aeolian transport, but the end of a production process starting from the retrieval of sand in the gravel pit and ending when lime slurry covers the surface of the quartz grain.

Archaeological doses are best evaluated by regenerative procedures, i.e. procedures which regenerate the natural dose by artificial irradiation in the laboratory. The most widely accepted procedure is the so-called $S A R$ protocol (single aliquot regeneration dose) presented by Murray and Wintle (2000) and Wintle and Murray (2006). Main feature of their protocol is an internal standardisation. As the OSL signals tend to increase after each registration, all signals are taken as the ratio to a constant test dose given subsequently to each laboratory irradiation. The success of this sensitivity correction is monitored by the recycling ratio calculated after repeated measurements. 


\section{Components within the luminescence emission}

Luminescence light contains several components which are differentiated according to their appearance after the beginning of the stimulation. They are attributed to different defect sites of the quartz crystal lattice (Bulur et al., 2000). While "fast" components show up immediately after the beginning of the stimulation, "slow" components show up several seconds later (visualisation of components s. Fig. 1). Fast bleaching is a pre-requisite for OSL-dating, therefore the analytical protocol of Wintle and Murray (2006) gives more weight to this component. Practically, the OSL signals are evaluated at the very beginning of the decay curve within the first 0.4-0.6 s. The advantage of this kind of treatment is that only the best bleached grains contribute to the archaeological dose, and hence the probability distribution is narrower.

Though slow decaying luminescence signals can often easily be detected visually in OSL decay curves, quantitative information on the relative contribution of fast and slow components can only be obtained from a linear modulated OSL-record (LM-OSL). This is obtained by linearly increasing the intensity of the stimulation light from 0 to $100 \%$ while the luminescence signal is recorded as a function of time. In these LM-records the luminescence light components appear one after another. Fig. 1 shows two possible types of emission behaviour. Bulur (2000) attributes the first peak in the LM-OSL curve to the fast bleaching component of the luminescence light. It is directly proportional to the irradiation dose and saturates at $100 \mathrm{~Gy}$, it is thermally stable up to $280^{\circ} \mathrm{C}$. The relative magnitude of early/late light can be used as a first tool to decide on the datability of mortar samples. If the first peak in the LM-record is equal or smaller than the second, Jain et al. (2005) suggest to isolate the fast com-

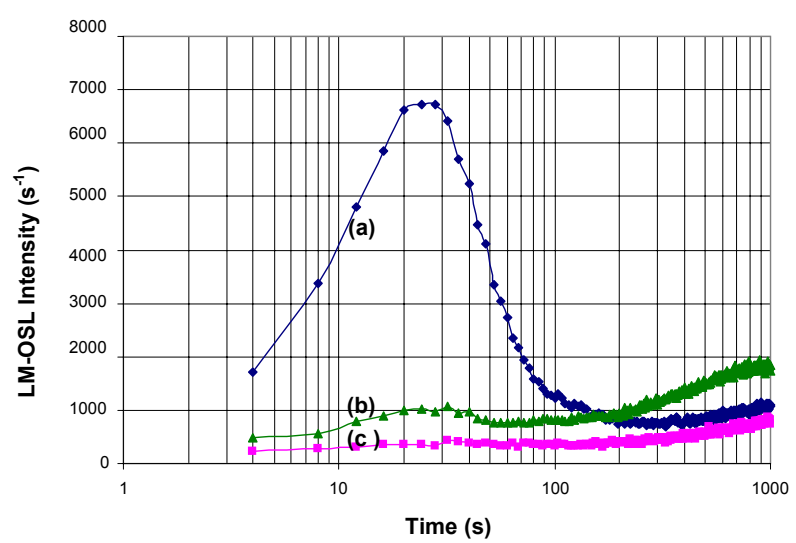

Fig. 1. Linearly modulated OSL for three samples (a) TRI4, (b) TRI6 and (c) DRS2 after irradiation with (a) $30 \mathrm{~s}$, (b) and (c) $120 \mathrm{~s}$. While TRI4 shows a well resolved fast component at $30 \mathrm{~s}$, the slow components are more intense than the fast component in samples TRI4 and DRS2. ponent by stimulating the quartz grains with infra-red $(830 \mathrm{~nm})$ light. The procedure is time consuming and requires medium to high emission signals.

\section{Level of depletion}

First papers on mortar dating (Zacharias et al., 2002; Goedicke, 2003) already mention the high proportion of outlying/unreasonable results. Indeed, many of the early attempts yielded Holocene ages; the dates correspond not to the date of mortar manufacturing, but to the date of the glaciofluvial deposition of the sand sediment during the Pleistocene. Transport mechanisms during these times were certainly slow enough to guarantee total bleaching of the sediment. Comparatively, the transport in case of mortar production proceeds faster, hence the chance of bleaching the sand is much smaller. Consequently, quartz grains of the mortar will be only partly bleached or even not at all, depending on the individual circumstances of the mortar production. Knowing the degree of bleaching is, therefore, one of the essentials at the beginning of the dating analysis.

There exist no unambiguous recipes to determine the degree of bleaching in sediments. One should be mentioned here for which experimental experience has been obtained. Agersnap Larsen et al. (2000) use samples of well defined depletion states which they irradiate by a known dose. Subsequently, the dose of these samples is reconstructed using a regeneration technique. The ratio between the natural OSL and the regenerated OSL should be 1 , if the sample was previously totally bleached (no residual geological signal), and it should be larger than 1, if the sample retains a residual signal, i.e. was not fully reset. The technique was designed for laboratory samples and is comparatively fast, but it also works well with natural samples, once a number of samples are averaged.

\section{Sunlight bleaching}

More information on the datability of mortar can be obtained by sunlight bleaching (Aitken, 1998, p. 19 and Table 6.1). Aside of the bleaching velocity these experiments reveal information which final state can be reached after exposition to sunlight. Fig. 2 shows that the time to reach the final state can be very different for different samples. The faster the decay and the lower the final light level, the more likely it is that the sample was sufficiently bleached to be dated by OSL. Sunlight bleaching is the fastest among all tests to predict whether mortar is datable by conventional methods.

\section{Single grain analysis}

When reducing the number of well bleached grains in a mortar sample continuously, a point will be reached from which correct dates cannot be obtained anymore. This lowest bleaching level cannot be defined precisely, but may be found in the order of magnitude around 5\%, depending on the emission intensity of the grains. Be- 


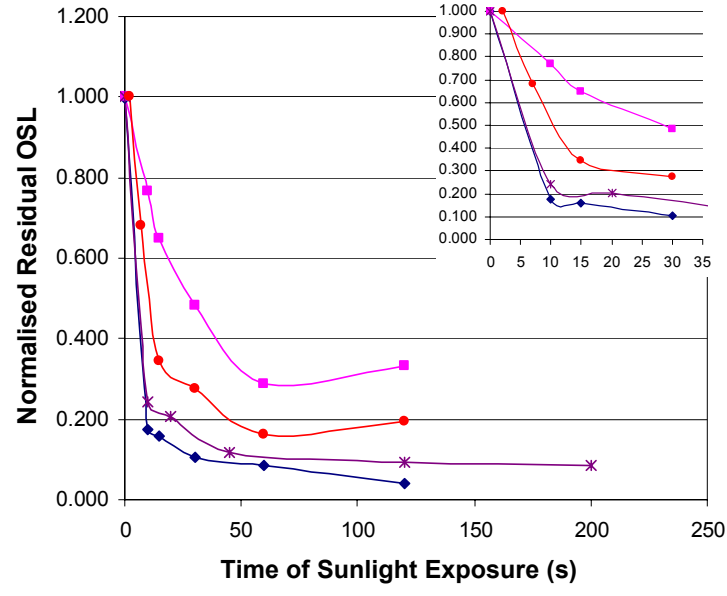

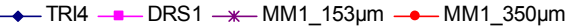

Fig. 2. Forms of decay of OSL signal during sunlight exposure for datable (TRI4 and MM1) and not datable (DRS1) samples. The velocity of the decay indicates the datability: mortar samples retaining $50 \%$ of the initial OSL after $50 \mathrm{~s}$ of sunlight exposure are unlikely to be datable by OSL.

yond this level the analysis of single grains is the only way to obtain the date of manufacture.

Single grain analysis has been introduced by BøtterJensen et al. (2000b). A laser beam (Nd: $\left.\mathrm{YVO}_{4}\right)$, emitting at $532 \mathrm{~nm}$, is focussed on single grains of $100-250 \mu \mathrm{m}$ sitting in an array of holes of a $9.7 \mathrm{~mm}$ diameter disk. The high intensity of the laser beam causes the OSL signal to decay 100 times faster (within $0.4 \mathrm{~s}$ ) than in conventional OSL. Although the method works very fast, the drawback is that only $5 \%$ of all grains deliver detectable signals (Duller et al., 2000) and further criteria of acceptance may reduce the overall yield of the analysis to $\sim 0.5 \%$. About 10000 grains, requiring roughly 30 days of analysis, are likely to yield meaningful archaeological doses (Jain et al., 2004).

\section{DOSE RATE MEASUREMENTS}

The fraction of fine grains in conventional lime mortar is usually very small, mostly grains $>100 \mu \mathrm{m}$ are taken for analysis. As the contribution of the alpha irradiation is removed during etching, only the beta, gamma and cosmic ray dose needs to be taken into account, the total dose rate being the sum of the following quantities:

$\dot{D}=\dot{D}_{\beta}+\dot{D}_{\gamma}+\dot{D}_{\cos m i c}$

\section{Beta dose rate}

For measuring the above quantities a number of direct (beta dosimetry using thin layer detectors: Göksu et al., 1999; El-Faramawy et al., 2004) and indirect measure- ments (ICP/MS analysis: Bailey et al., 2003; Preusser and Kasper, 2001; beta counting: Ankjærgaard and Murray, 2007; neutron activation analysis) are available. However, for mortar dating gamma spectrometry should be preferred (Gilmore, 2008). Gamma spectra not only allow the determination of the nuclides ${ }^{238} \mathrm{U},{ }^{232} \mathrm{Th}$ and ${ }^{40} \mathrm{~K}$, the decay of which give rise to the dose rate, they also allow information onto whether these nuclides fulfil the condition of the radioactive equilibrium ${ }^{1}$. Radioactive equilibrium is the pre-requisite for the application of the conventional factors converting concentration into activity values (Adamiec and Aitken, 1998). If no such equilibrium exists, the dose rate to quartz was not constant during archaeological times and hence, the conversion factors cannot be applied. In that case, the dose rate has to be determined according to a sophisticated iterative procedure, as suggested by Degering and Krbetschek (2007).

Reasons for the deviation from radioactive equilibrium are different mobilities/solubilities of nuclides or their oxides within the mortar matrix under environmental conditions. It seems likely that specific nuclides (possibly in form of the oxide $\mathrm{UO}_{2}{ }^{++}$) are incorporated selectively in the crystal lattice of calcite during solidification of the lime. Fixation of these nuclides may then cause mobility differences in the mortar. When exposed to weathering, as was the case in the Roman Theatre, differences in mobility become more pronounced. Because of short half live times of the nuclides of the ${ }^{232} \mathrm{Th}$ decay chain, no disequilibrium can be observed in this decay chain.

When the arithmetic mean of the activities of the ${ }^{238} \mathrm{U}$ daughter nuclides are used for age calculation, despite the disequilibrium is clearly shown in the gamma spectrum, a small but not negligible difference to the OSL age corrected for disequilibrium is obtained (see Table 1).

Table 1.

\begin{tabular}{lccc}
\hline Sample No. & $\begin{array}{c}\text { Ages without } \\
\text { disequilibrium } \\
\text { correction }\end{array}$ & $\begin{array}{c}\text { Ages after } \\
\text { ADELE } \\
\text { correction }\end{array}$ & Error \\
\hline [a] & [a] $^{*}$ & $\pm[\mathrm{a}]$ \\
\hline MM1 & 1516 & 1573 & 156 \\
MM3 & 1556 & 1590 & 161 \\
MM5 & 1661 & 1698 & 208 \\
MM6 & 1514 & 1559 & 162 \\
MM7 & 1713 & 1750 & 203 \\
MM8 & 1601 & 1662 & 178 \\
\hline
\end{tabular}

* Reference year: 2004
${ }^{1}$ Radioactive equilibrium exists when the activities of mother and daughter nuclides are equal and invariant over time (over the archaeological storage times) 


\section{Gamma dose rate/Cosmic dose rate}

More often than not mortar samples of sufficient size can only be removed from inhomogeneous locations of a building (Fig. 3). The inhomogeneity and the large range of gamma radiation recommend that the measurements of the environmental dose rate (i.e. gamma dose rate plus cosmic dose rate) should be made at exactly the position where the sample has been removed. A suitable and safe method of measurement is dosimetry using thermoluminescent dosimeters (TLDs), among which aluminium oxide $\left(\alpha-\mathrm{Al}_{2} \mathrm{O}_{3}: \mathrm{C}\right)$ has proven as the most suitable material, because of its high sensitivity and its energy dependence being equal to quartz. The advantage of these detectors is that they can be packed in small capsules $(15 \times 33 \mathrm{~mm})$ of thin walled aluminium or thick walled Perspex and can exactly be positioned in a $4 \pi$-geometry. Three or more detectors per capsule are recommended. The time of exposition should be 3 to 5 months, shorter periods are possible at the cost of accuracy. For the evaluation standard TL/OSL-readers, adapted for dosimetry purposes (Goedicke, 2006), may be used. Because of the larger dimensions of the relevant detector heads, gamma spectrometry or gamma counters proved impractical in respect of exact positioning.

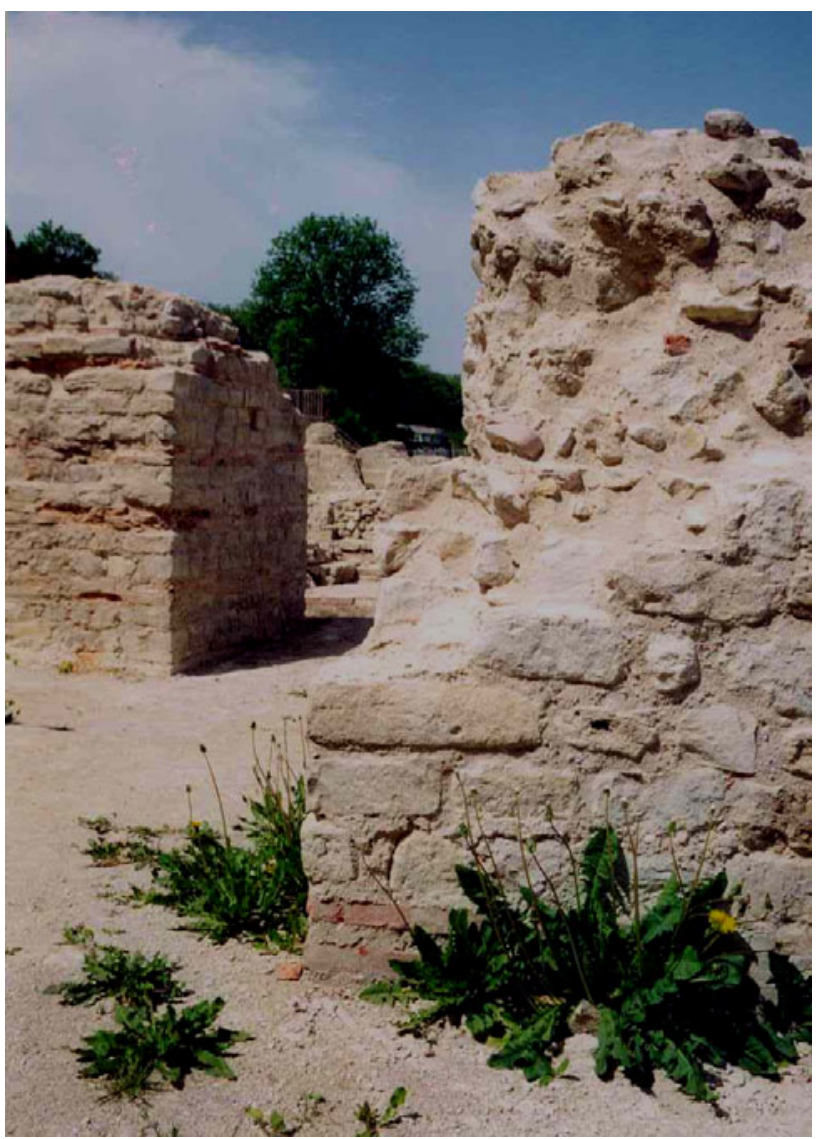

Fig. 3. Pillars of the sub-construction of the Roman Theatre at Mainz, showing the inhomogeneous environment of mortar and recommending TLD measurements for environmental dose rate determination.
In case the beta dose rate is small compared to the total dose rate, the age will become a function of the gamma dose rate (see Eq. 4.1 above). Frequently, the proportion of the latter exceeds $50 \%$ of the total dose rate and thus determines the age and the error. Hence, the environmental dose rate deserves great attention.

\section{RESULTS AND DISCUSSION}

It has been shown earlier (Goedicke, 2003) that large grains of mortar are more readily bleached than small grains, because large grains tend to move to the surface when mixed together with smaller ones. Therefore, in the series of the Roman Theatre a grain size fraction of $350 \mu \mathrm{m}$ was selected, and these grains were found to consist of individual items, not agglomerates. Although the degree of bleaching may be better with the larger grains, a drawback may arise because of the lower emission intensity.

The simple SAR protocol (Murray and Wintle, 2000) was used for the Roman Theatre samples, but as far as pre-heat temperatures are concerned it was not followed literally. Pre-heating the sample after laboratory irradiation is a necessary step to remove unstable OSL signals that would have decayed in natural samples. It is a general observation of the authors that pre-heats beyond $210^{\circ} \mathrm{C}$ given to young $(<2 \mathrm{ka}$ old $)$ fired samples do not improve the archaeological dose estimate. Recycling ratios, sensitivity changes and the recuperation values increase steadily with pre-heat temperature from $200^{\circ} \mathrm{C}$ onwards. The observation is restricted to fired matter only, sediments regularly require higher pre-heats and cut-heats. It was therefore decided to use a conservative pre-heat temperature of $190^{\circ} \mathrm{C}$ and a pre-heat temperature of the test dose of $150^{\circ} \mathrm{C}$.

Some of the Theatre samples showed blue light emission upon stimulation with red diodes $(880 \mathrm{~nm})$. At the time of the investigation this emission was attributed to feldspar contamination, however, Jain et al. (2005) describe also a blue emission from quartz upon stimulation with laser diodes $(830 \pm 10 \mathrm{~nm})$ at elevated temperatures. The isolation of the pure quartz signal was achieved by using the "double SAR" protocol (Banerjee et al., 2001), which comprises two types of stimulation: one IRstimulation for bleaching the contamination signal followed by a blue stimulation for bleaching the quartz signal.

Between 48 and 153 single aliquots were measured for each sample. From the group of data the minimum archaeological dose (this is the dose accumulated since the mortar was mixed) was extracted by using the radial plot (Galbraith et al., 1999). This dose was found by selecting a central value such that the $\pm 2 \sigma$ error band includes the lower dose edge of the data. The archaeological dose was then calculated as the weighted mean from the data points within the $\pm 2 \sigma$ band. 
Data for the internal dose rate were obtained from gamma spectrometric measurements using a thin $(19.2 \mathrm{~mm})$ planar HPGe detector (Ortec LO AX Series HPGe, POP TOP). The detector allows the evaluation of low energy peaks of the uranium decay chain (e.g. ${ }^{234} \mathrm{Th}$ at $63.3 \mathrm{keV}$ ), thus allowing estimates of the existence of the decay equilibrium. Four spectra were averaged to compensate for the low sensitivity of the detector. Fig. 4 shows the activities of nuclides in the decay chain of ${ }^{238} \mathrm{U}$ for five samples from the Roman Theatre. All samples show a distinct drop of activity within the initial members of the ${ }^{238} \mathrm{U}$ decay chain, the disequilibrium seems to begin between nuclides ${ }^{234} \mathrm{U}$ and ${ }^{214} \mathrm{~Pb}$. On which way the disequilibrium establishes was not investigated within the framework of this paper, the poor solubility of uraniumcarbonate is a likely reason.

Despite the gamma spectra indicate that the dose rate was not constant over archaeological times, an OSL age can be derived using the software ADELE (Degering and Krbetschek, 2007). Table 1 compares the OSL ages for the Theatre samples with and without the disequilibrium correction.

The comparison clearly illustrates that the deviation from the equilibrium, in some instances rather severe $\left(\sim 40 \%\right.$ loss of activity between ${ }^{234} \mathrm{Th}$ and $\left.{ }^{214} \mathrm{~Pb}\right)$, causes an age underestimation of $\sim 40$ years, i.e. $\sim 2.5 \%$ of the total age. In historic periods this difference is meaningful and cannot be neglected. Hence, simplifications in evaluating the internal dose rate in case of radioactive disequilibrium may be inadequate, even when the total age is comparatively small. It becomes obvious from this example that dose rate measurements aiming only at the con-

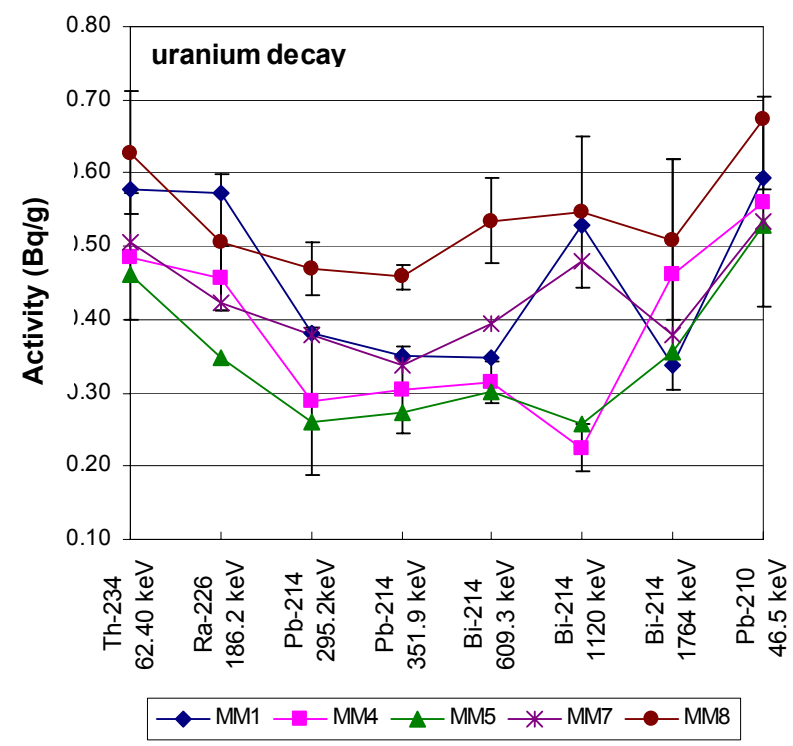

Fig. 4. Measured activities of nuclides in the decay chain of uranium for mortar samples from the Roman Theatre. Activity data are mean values of four measurements. The standard deviation is shown for two samples only (MM4 and MM8) for clarity. The high values for ${ }^{210} \mathrm{~Pb}$ may be due to environmental deposition. centration of $\mathrm{U}$ or Th (i.e. ICP/MS, neutron activation) may cause incorrect ages, although the analytical measurements may be correct. Gamma spectrometry is the only valid method of dose rate determination for mortar dating.

The environmental dose rate was determined by TLD measurements using $\mathrm{Al}_{2} \mathrm{O}_{3}: \mathrm{C}$ and an exposition period of $\sim 180$ days. From the six single results presented in the above table the final context age for the Roman Theatre mortar is obtained as $\mathrm{AD} 374( \pm 33, \pm 94)^{2}$, in fair agreement with unpublished archaeological findings mentioned in section 2 .

Procedures and protocols described above for dose determinations of the Theatre samples were also applied for samples from the Roman Bath, the Drusus Monument and the Roman Aqueduct. Except for two samples from the Roman Bath no archaeologically meaningful results could be achieved. For the latter samples (TRI3 and TRI4) archaeological doses could be obtained that well correspond to Roman occupancy. However, as the site is now covered by modern constructions, measurements of the environmental dose rate were not feasible and, hence, no final OSL age estimates could be established. If one would use, for comparison, the results of the TLD measurements of the Roman Theatre for the age estimation of the Roman Bath, an age within the first two centuries AD would result.

Searching for the reason of the failure of the remaining seven samples, the components of the light emission were investigated using LM-OSL. The LM-OSL plot of Fig. 1 shows a very distinct fast component after $30 \mathrm{~s}$ of stimulation for sample TRI4, whereas for samples TRI6 and DRS2 the corresponding fast signals are much smaller, and the slow components, appearing after $\sim 400 \mathrm{~s}$, exceed the fast component. Hence, bleaching of these latter two samples proceeds very reluctantly and has obviously not been achieved while the mortar was manufactured. Correspondingly, the archaeological doses obtained from these samples yielded 15 and more Gy, indicating Holocene ages. For comparison, doses obtained for the two samples from the Roman Bath TRI3 and TRI4 were almost one order of magnitude lower (3.3 and $3.8 \mathrm{~Gy})$.

However, a fast emission peak does not guarantee datability; even fast decaying samples may not be totally bleached. The degree to which the two samples TRI3 and AQP1 (datable and not datable) were bleached was investigated by using the method by Agersnap Larsen et al. (2000). Four different states of depletion were produced by bleaching aliquots for $0,10,100,1000 \mathrm{~s}$. A standard dose of 12.5 Gy was added on top of these aliquots, and this dose was regenerated. The ratio of the natural to the regenerated LM-OSL for the two samples (Fig. 5) allows a clear distinction between fully and partially reset sam-

\footnotetext{
${ }^{2}$ Terms in the bracket: \pm 33 arithmetic mean of single results, \pm 94 context error
} 
ples. Within the first $50 \mathrm{~s}$ of the LM-OSL the ratios for sample TRI3 do not deviate very much from 1, indicating that the dose of 12.5 Gy could be regenerated fairly well. But yet, a small amount of residual geological OSL seems to be present in this sample. Conversely, the ratio for the unbleached aliquot of AQP1 is definitively larger 1 . By bleaching the ratio of 1 is approached, but the dose of 12.5 Gy could not be fully regenerated even after bleaching for $1000 \mathrm{~s}$. The region in Fig. 5 between 50 and $1000 \mathrm{~s}$ visualizes the low bleaching velocity for the slow component. It should be noted that the curves shown are from natural samples which declares the large scatter in sample TRI3. A prerequisite of the above method is that the fast component of the OSL emission is well detectable.
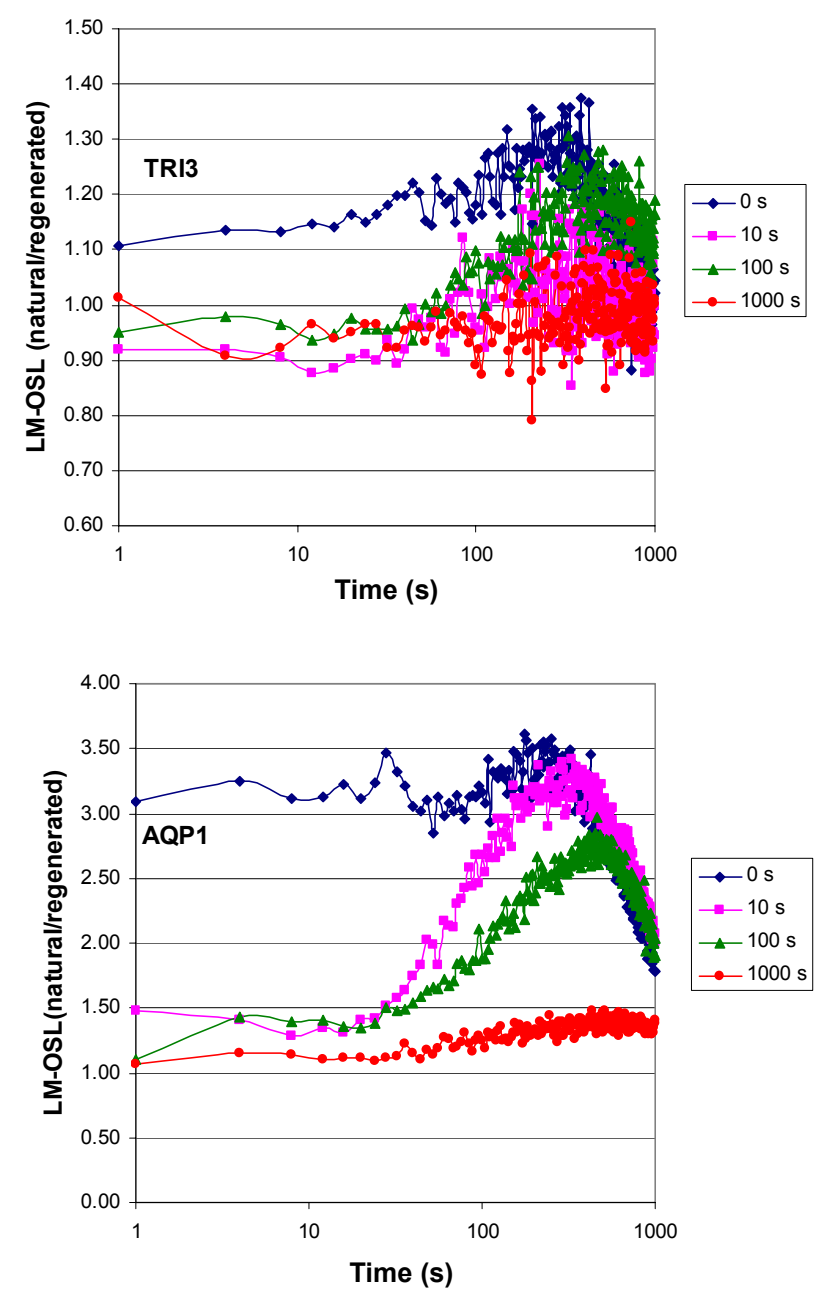

Fig. 5. Ratio of natural to regenerated LM-OSL signals for four different bleaching levels. TRI3 shows a small contribution from a slow component, but bleaches rapidly, the scatter indicating that the data are obtained from low intensity signals. AQP1 exhibits a large slow component which is not fully bleached even after $1000 \mathrm{~s}$. The ratio of the unbleached aliquot (natural/regenerated OSL >3.0) indicates a geological dose residue and precludes this material from being dated by blue OSL.
Samples, the fast OSL emission of which is weak, are best subjected to sunlight bleaching in order to gain information on the degree of depletion. From the decay of four samples shown in Fig. 2 it may be deduced that the zero-setting event for well datable samples is a matter of a few seconds: the sample TRI3 from the Roman Bath is $90 \%$ reset after $30 \mathrm{~s}$, whereas the sample DRS1 from the Drusus Monument still retains $50 \%$ of its emission intensity after that time. Resulting from these observations it can be anticipated that samples are probably datable when $20 \%$ of the initial emission intensity is remaining after $30 \mathrm{~s}$ of sunlight exposure.

As a result of LM-OSL investigations of the mortar samples only two (TRI6 and DRS2) raised doubts of being datable by conventional blue OSL due to an appreciable slow emission component. In the remaining five samples the level of depletion was too low for multiple grain methods to produce archaeological doses, therefore the single grain analysis remained as the only promising method. The partially bleached sample from the Roman Aqueduct AQP1 was selected as example because of its fast decay characteristic. The standard SAR procedure for single grain analysis was applied on 2000 grains using a test dose of $300 \mathrm{~s}$, regeneration doses of $60,120,240,0$, $120,500 \mathrm{~s}$ and a laser irradiation time of $4 \mathrm{~s}$. Thirty valid results could be extracted by using the radial plot technique, the weighted mean of these yielded a dose of $\sim 3.0 \mathrm{~Gy}$, indicating the erection of the Aqueduct in the first half of the first century AD. Historical records quote a date of erection in 70-80 $\mathrm{AD}$. We are well aware that the number of single grains investigated was too low to obtain a proper dose distribution, the high time demand, however, prevented us from conducting further analyses.

\section{CONCLUSION}

From various preliminary experiments it could be deduced that seven out of the 14 samples presented above were datable by standard blue OSL. For another five samples the bleaching level was too low for standard procedures to be applicable. A strong slow OSL decay combined with a very low level of bleaching precluded two samples from dating.

To predict whether quartz from mortar can be dated by OSL, it is essential to investigate the ratio of the fast to slow component of the OSL emission and the degree of depletion. In case the fast component is seen to be prevailing, a test on the level of bleaching should be the next step. If a strong fast component is met in a fairly bleached sample, standard procedures for dose determination may be successful, however, if very low levels of bleaching are encountered, the only way finding the archaeological dose is by single grain analysis. In this case a few thousands grains should be investigated in order to obtain a reasonable number of results at the low dose edge of the dose distribution. For samples with prevailing slow component the archaeological dose needs to be 
measured from the UV-emission of quartz upon IR stimulation, given the light signal is high enough, following the analytical procedure of Jain et al. (2005).

While the evaluation of the archaeological dose more or less follows standard procedures, care should be taken for the dose rate measurements. We recommend methods that focus on the radioactive decay equilibrium; it could be shown that radioactive disequilibrium leads to non negligible deviation from the true age. At present low level gamma spectrometry seems to be the only analytical tool to enable such investigations.

\section{ACKNOWLEDGEMENTS}

The experiments were conducted while the author was guest scientist at the Geographical Institute of Humboldt University of Berlin. The author gratefully acknowledges the contribution of Dr. Jens Dolata for supplying samples and imparting the historical background. The invaluable support received by Dr. M. Haustein (CEZA, Mannheim, ADELE computations) and by Dr. C. Woda (German Research Centre for Environmental Health Institute of Radiation Protection, Neuherberg, single grain analyses) is equally gratefully acknowledged.

\section{REFERENCES:}

Adamiec G and Aitken M, 1998. Dose-rate conversion factors: update. Ancient TL 16(2): 37-50.

Aitken MJ, 1998. An Introduction to Optical Dating. Oxford, Oxford University Press: $276 \mathrm{pp}$.

Agersnap Larsen N, Bulur E, Bøtter-Jensen L and McKeever SWS, 2000. Use of the LM-OSL technique for the detection of partial bleaching in quartz. Radiation Measurements 32(5-6): 419-425, DOI 10.1016/S1350-4487(00)00071-8.

Ankjærgaard C and Murray AS, 2007. Total beta and gamma dose rates in trapped charge dating based on beta counting. Radiation Measurements 42: 352-359, DOI 10.1016/j.radmeas.2006.12.007.

Bailey RM, Stokes S and Bray H, 2003. Inductively-coupled plasma mass spectrometry (ICP/MS) for dose rate determination: some guidelines for sample preparation and analysis. Ancient TL 21: 11-15.

Bailiff IK, 2007. Methodological developments in the luminescence dating of brick from English late-medieval and post-medieval buildings. Archaeometry 49: 827-851, DOI 10.1111/j.14754754.2007.00338.x.

Banerjee D, Murray AS, Bøtter-Jensen L and Lang A. 2001. Equivalent dose estimation using a single aliquot of polymineral fine grains. Radiation Measurements 33(1): 73-93, DOI 10.1016/S13504487(00)00101-3.

Bøtter-Jensen L, Solongo S, Murray AS, Banerjee D and Jungner H. 2000a. Using OSL single-aliquot regenerative-dose protocol with quartz extracted from building materials in retrospective dosimetry. Radiation Measurements 32(5-6): 841-845, DOI 10.1016/S1350-4487(00)00066-4.

Bøtter-Jensen L, Bulur E, Duller GAT and Murray AS, 2000b. Advances in luminescence instrument systems. Radiation Measurements 32(5-6): 523-538, DOI 10.1016/S1350-4487(00)00039-1.

Bulur E, Bøtter-Jensen L and Murray AS, 2000. Optically stimulated luminescence from quartz measured using the linear modulation technique. Radiation Measurements 32(5-6): 407-411, DOI 10.1016/S1350-4487(00)00115-3.

Degering D and Krbetschek MR, 2007. Dating of interglacial sediments by luminescence methods. In: Developments in Quarternary Sci- ence 7:157-172. Series editor: Jaap JM van der Meer. Elsevier.

Duller GAT, Bøtter-Jensen L and Murray AS, 2000. Optical dating of sand-sized quartz: sources of variability. Radiation Measurements 32(5-6): 453-457, DOI 10.1016/S1350-4487(00)00055-X.

El-Faramawy NA, Göksu HY and Panzer W, 2004. Thermoluminescence dosimetry properties of a new thin beta detector $(\mathrm{LiF}: \mathrm{Mg}$, $\mathrm{Cu}, \mathrm{P} ; \mathrm{Gr}-200 \mathrm{~F}$ ) in comparison with highly sensitive $\mathrm{Al}_{2} \mathrm{O}_{3}: \mathrm{C}$ beta dosimeters. Journal of Radiological Protection 24: 273-282, DOI 10.1088/0952-4746/24/3/006.

Fleming SJ, 1979. Thermoluminescence Techniques in Archaeology. Oxford, Clarendon Press: 233 pp.

Galbraith RF, Roberts RG, Laslett GM, Yoshida H, Olley JM, 1999. Optical dating and multiple grains of quartz from Jinmium rock shelter, Northern Australia: part I experimental design and statistical models. Archaeometry 41(2): 339-364, DOI 10.1111/j.14754754.1999.tb00987.x.

Gilmore G, 2008. Practical Gamma-Ray Spectrometry. New York, John Wiley: $424 \mathrm{pp}$.

Goedicke C, 2003. Dating historical mortars by blue OSL: results from known age samples. Radiation Measurements 37: 409-415, DOI 10.1016/S1350-4487(03)00010-6.

Goedicke C, 2006. Assessment of environmental dose rates in luminescence readers using $\alpha-\mathrm{Al}_{2} \mathrm{O}_{3}: \mathrm{C}$. Radiation Measurements 41: 36 39, DOI 10.1016/j.radmeas.2005.02.006.

Goedicke C and Dolata J, 2007. Unpublished.

Göksu HY, Bulur E and Wahl W, 1999. Beta dosimetry using thin-layer $\alpha-\mathrm{Al}_{2} \mathrm{O}_{3}: \mathrm{C}$ TL detectors. Radiation Protection Dosimetry 84(1-4): 451-455.

Hale J, Heinemeier J, Lancaster L, Lindross A and Ringbom Å, 2003. Dating ancient mortar. American Scientist : 91, $130 \mathrm{ff}$, DOI 10.1511/2003.2.130

Jain M, Thomsen KJ, Bøtter-Jensen L, Murray AS, 2004. Thermal transfer and apparent-dose distributions in poorly bleached mortar samples: results from single grains and small aliquots of quartz. Radiation Measurements 38: 101-109, DOI 10.1016/j.radmeas.2003.07.002.

Jain M, Murray AS, Bøtter-Jensen L and Wintle AG, 2005. A singlealiquot regenerative-dose method based on IR $(1.49 \mathrm{eV})$ bleaching of the fast component in quartz. Radiation Measurements 39: 309318, DOI 10.1016/j.radmeas.2004.05.004.

Lindroos A, Heinemeier J, Ringbom A, Braskén $\mathrm{M}$ and Sveinbjörnsdóttir Á, 2007. Mortar Dating Using AMS ${ }^{14} \mathrm{C}$ and Sequential Dissolution: Examples from Medieval, Non-Hydraulic Lime Mortars from the Åland Islands, SW Finland. Radiocarbon 49: 47-67.

Martini M and Sibilia E, 2006. Absolute dating of historical buildings: the contribution of thermoluminescence (TL). Journal of Neutron Research 14: 69-74, DOI 0.1080/10238160600673326.

Murray AS and Wintle AG, 2000. Luminescence dating of quartz using an improved single-aliquot regenerative-dose protocol. Radiation Measurements 32(1): 57-73, DOI 10.1016/S1350-4487(99)00253-X.

Nawrocka D, Michiniewicz J, Pawlyta J and Pazdur A, 2005. Application of radiocarbon method for dating of lime mortars. Geochronometria 24: 109-115.

Preusser F and Kasper HU, 2001. Comparison of dose rate determination using high-resolution gamma spectroscopy and inductively coupled plasma-mass spectrometry. Ancient TL 19: 19-23.

Scharf A, 2007. Datenanalyse und Qualitätssicherung der 14CAMSMessungen am Erlanger Tandembeschleuniger und Erweiterung des Sortiments 14C-datierbarer Probenmaterialien. Unpublished $\mathrm{PhD}$ thesis, Friedrich-Alexander University, ErlangenNürnberg.

Wintle AG and Murray AS, 2006. A review of quartz optically stimulated luminescence characteristics and their relevance in singlealiquot regeneration dating protocols. Radiation Measurements 41: 369-391, DOI 10.1016/j.radmeas.2005.11.001.

Zacharias N, Mauz B and Michael CT, 2002. Luminescence quartz dating of lime mortars. A first research approach. Radiation Protection Dosimetry 101: 379-382. 